\title{
More than Technique
}

\section{Dear Reader,}

An eventful 2015 is now drawing to a close. Perhaps you will use the less stressful days until the New Year not only to read this December issue but also to browse through the six previous magazines and look back on some events. Many of the articles record the dramatic changes that the automotive industry has undergone in the past few months, and is still undergoing. By tradition, you can find best-practice articles from all sectors of automotive electronics, although there is a clear trend towards high-voltage systems, a dual-voltage on-board power system that is still in need of re-organisation, IT and software topics and innovations in consumer electronics.

It has always been the case that best-practice articles with technical depth form the basic framework of ATZelektronik. However, the documentation of progress has also been supplemented by critical authors' contributions, which have gained in expressiveness compared to previous years - motivated by intensive background discussions that the editorial team has also been able to use for their own opinion-forming articles and interviews.

So now we are moving into 2016, a year in which the same topics will be subject to even more heated debate. The discussion concerning the feasibility of postlithium-ion batteries and more energyintensive lithium-ion batteries must definitely be carried out on a higher quality level. And so must the issue of IT security for the connected car. In this context, it will continue to be very exciting to see how and with which IT companies and digitisation programs the car makers will be able to sustainably position themselves. Cryptography, data encryption that is as secure as possible and the impact on future on-board power systems will therefore be among the new topics focused on by ATZelektronik in 2016.
As already discussed in the 2015 issues, some experts are questioning the functional safety of driver assistance systems aimed at making high-level automation possible, as they feel that development and testing methods are not viable in the long term. The same applies to software development. We should continue to discuss with these experts in the year to come, ideally on the platform offered by ATZelektronik.

Our joint publications reflect those topics that are influencing the industry. However, the picture is not complete. After all, technical articles alone project only part of the whole. For that reason, we zoom out in the sense of good technology marketing to give engineers better orientation. This concept has been well received, but admittedly there is always room for improvement. We need to become more international. What is happening, for example, behind the scenes in Silicon Valley or in China? The 1/2016 issue will provide the first evidence of this wider approach both in its contents and in our publication concept. Prepare to be surprised.

I wish you a Merry Christmas and a Happy New Year,

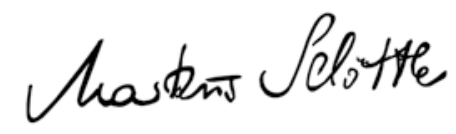

Markus Schöttle

Deputy Editor in Chief

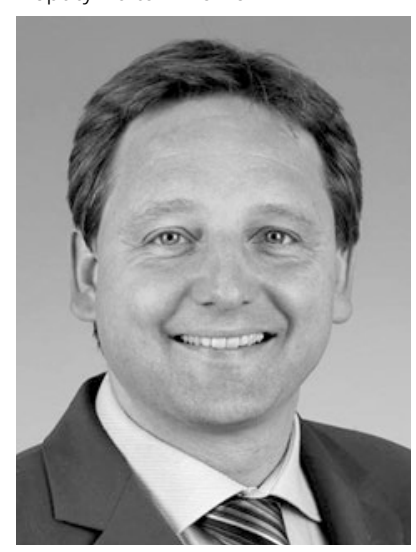

